\title{
A Case Study and the Lessons Learned from In-House Alcohol Based Hand Sanitizer Production in a District Hospital in Rwanda
}

\author{
April Budd1, Stephanie Lukas², Unarose Hogan'3, Kamugisha Priscille", Kanamugire Fanny4, \\ Pauline Hill ${ }^{5}$, Ndikumana Edouard ${ }^{4}$, Jean Bosco Byukusenge ${ }^{4}$, Ntigurirwa Placide ${ }^{4}$, \\ Mutayomba Aimable4, Rex Wong 1 \\ ${ }^{1}$ Global Health Leadership Institute, Yale University, New Haven, CT, USA \\ ${ }^{2}$ St. Louis College of Pharmacy, St. Louis, MO, USA \\ ${ }^{3}$ New York University, New York, USA \\ ${ }^{4}$ Muhima Hospital, Kigali, Rwanda \\ ${ }^{5}$ Duke University, Durham, NC, USA \\ Email: rex.wong@yale.edu
}

Received 24 February 2016; accepted 8 April 2016; published 13 April 2016

Copyright (C) 2016 by authors and Scientific Research Publishing Inc.

This work is licensed under the Creative Commons Attribution International License (CC BY). http://creativecommons.org/licenses/by/4.0/

(c) (i) Open Access

\section{Abstract}

Health-care-associated infections (HCAIs) are a major global safety concern for patients, healthcare professionals and public health particularly in developing countries where access to hand washing facilities is limited due to infrastructure. Alcohol-based hand sanitizer offers a viable alternative where water sources are unreliable or insufficient. However, in resource-limited settings, the introduction of alcohol-based hand sanitizer has been slow due to economic, manufacturing and procurement challenges compounded by the lack of evidence as to its acceptability in varying organizational cultures. This case study describes the process of producing, educating, distributing, scaling up and monitoring the impact of a quality improvement project to locally produce alcohol based hand sanitizer using the formula provided by the World Health Organization in a district hospital in Rwanda. During a 10-month implementation, hand sanitizer was made available to all departments of the hospital and all hospital staff received training on the proper use and ordering of the product. The overall hand hygiene compliance using any method significantly increased from $59 \%$ pre intervention to $67 \%$ post intervention $(P<0.001)$. Specifically, the use of hand sanitizer for hygiene significantly increased from $46 \%$ to $58 \%(P<0.001)$. By producing hand sanitizer in-house, the hospital saved $71 \%$ when compared to purchasing commercial products. The use of hand sanitizer is not a replacement for running water in the hospital. However, with the lack of proper infrastructure, making hand sanitizer available is an acceptable alternative to improve the infection prevention and control standard. The production of hand sanitizer within a health care facility is cost effective and is feasible to integrate into existing opera-

How to cite this paper: Budd, A., et al. (2016) A Case Study and the Lessons Learned from In-House Alcohol Based Hand Sanitizer Production in a District Hospital in Rwanda. Journal of Service Science and Management, 9, 150-159. 
tions. The team is working with the Rwandan Ministry of Health to introduce the program to all public hospitals as a national program.

\title{
Keywords
}

\author{
In-House Production of Hand Sanitizer, Resource-Limited Setting, Hand Hygiene, \\ Hospital Acquired Infection, Quality Improvement
}

\section{Introduction}

Health-care-associated infections (HCAIs) are a major global safety concern for patients, health-care professionals and public health with an estimated 1.4 million plus people at any time worldwide suffering from HCAIs in health-care facilities [1]-[3]. In developed counties, HCAI rates range from 5\% - 10\% [4]. In the United States alone, HCAIs accounted for approximately 90,000 deaths and 30 billion US dollars a year in excess health care cost [2] [5]-[8]. In developing countries, the magnitude of the problem can exceed 25\%, attributing to morbidity and mortality [4] [9] [10]. The increased morbidity and mortality, prolonged hospital stays, and excessive costs caused by HCAIs are frequently preventable through proper hand hygiene [8]-[10].

Despite the proof that proper hand-hygiene practice combats HCAIs [8] [11]-[27], compliance among health care workers has historically been very low, averaging worldwide 39\% [5] [11] [18]-[24]. The compliance rates were generally lower and varied hugely in many mid- to low-income countries, ranging from $6 \%$ to $38 \%$ [19] [25]-[28]. This variation is largely attributed to the infrastructural limitations, including insufficient hand washing stations, irregular water supply and shortage of hand washing products [19]-[29].

Many hospitals in Rwanda continue to face the above-mentioned challenges, including many district hospitals in Kigali. Founded in 2001, Muhima Hospital is a district hospital focusing on maternal and child health facility with 131 clinical staff. The hospital has a monthly average 638 births and 211 surgeries performed, in addition to 104 outpatient visits per day. The 149-bed hospital has only 10 hand washing stations in its clinical areas, with intermittent water supply from the city.

Sustainable interventions to improve hand-hygiene practice have been found to benefit from a multimodal approach including education, visual reminders, ongoing monitoring and feedback, as well as infrastructure changes [5] [11] [15] [16] [30]-[32]. In many low-income countries where access to hand washing facilities is limited due to infrastructural realities and where water sources are unreliable or insufficient, alcohol-based hand sanitizer offers a viable alternative. Evidences show that the introduction of alcohol-based hand sanitizer is associated with a higher hand-hygiene compliance rate [24], however, in resource-limited settings, the introduction of alcohol-based hand sanitizer has been slow. This reality is attributed to economic, manufacturing and procurement challenges compounded by the lack of evidence as to its acceptability in varying organizational cultures. Despite this there is evidence that it may be a feasible, cost effective solution when locally produced in the hospital and it is a recommended intervention by WHO [10] [33]-[35].

To improve hand hygiene compliance in Muhima Hospital, the Human Resources for Health (HRH) program with the support of the Ministry of Health of Rwanda [36] developed a program to locally produce alcohol based hand sanitizer using the formula provided by the WHO [37]. This paper describes the process of implementing the local production of hand sanitizer using a World Health Organization (WHO) formula at a district-level maternity hospital in Rwanda and examines the impact on hand hygiene adherence.

\section{Implementing the In-House Hand Sanitizer Production}

In September 2013, a multidisciplinary team (MDT) was formed in Muhima Hospital to serve as the working group to address the hand hygiene practice problem in the hospital. The MDT led by the hospital's Chief Pharmacist designed and conducted the phased roll-out intervention. The MDT included representation from Infection Prevention and Control (IPC), Environmental Health (Hygiene), Quality Improvement (QI), Nursing, Pharmacy and the Human Resources for Health's Infection Control Specialist and Health Management specialists. 


\subsection{Production}

In order to test the feasibility of the project, the MDT conducted a cost analysis and created a test batch of sanitizer based on a WHO formula (Appendix 1) in September 2013. To demonstrate to the hospital staff the efficacy and gain buy in, a test batch was assessed conducting a case-control pre- and post-hand swabs on a random selection of eight sets of hands. Four samples were cleansed with a commercially available product and the other four cleansed with the in-house manufactured test batch. The swabs were tested in the hospital laboratory for broad spectrum bacterial culture. The lab culture results showed the locally produced sanitizer has equal efficacy as the commercially bought products.

The team conducted a cost analysis and found a 71\% financial savings when producing in-house hand sanitizer rather than a commercially-bought sanitizer. After demonstrating the efficacy and analyzing cost analysis to ensure the in-house hand sanitizer production was a viable solution, the team sought the approval of the hospital's senior management team and buy-in from clinical leaders. Budgetary approval was obtained in December 2013 to initiate the purchase of equipment and supplies including the ingredients for the sanitizer, the containers for distribution and dispenser bottles for installation in each department and all units.

In January 2014, the MDT trained three hospital staff members to produce hand sanitizer following the WHO-recommended formula and protocol. The training included a review of the ingredients, mixing procedures, storage, production schedule, and ordering and distribution procedures.

\subsection{Education}

A series of hospital-wide training sessions were conducted to sensitize clinical and non-clinical staff on the appropriate use of the alcohol-based hand sanitizer by the infection control specialist, Infection Prevention and Control staff and Nursing Director. The WHO's “5 Moments of Hand Hygiene” and ' Hand Rub Technique” were the major contents of the training. ${ }^{11}$ Posters and guidelines were translated into Kinyarwanda, the native language of Rwanda, and were strategically placed throughout the hospital as visual reminders to staff as well as to patients and visitors. The training also included the ordering process, storage in the clinical unit, and usage tracking.

Regular re-sensitization trainings were provided to all staff to encourage behavior change, especially in the areas that the audits revealed to have the lowest utilization rates.

\subsection{Distribution}

Ordering and distribution processes were integrated into the existing hospital pharmacy systems. When the hand sanitizer in an individual clinical unit becomes low, the unit will follow the existing ordering procedures to make request. It was the intention of the MDT to strengthen the institutionalization of this process by not creating parallel mechanism for ordering and distribution of the hand sanitizer. Each week, the departments would order the quantity they need based on their expected consumption. The departments fill out the same requisition paperwork that they would for medications and supplies. The order would be submitted to the pharmacy department. The pharmacy department would in turn provide hand sanitizer to the departments according to the request. All department In-Charges and administrative designees were informed on the process for ordering to ensure a continual supply.

\subsection{Phased Implementation}

The implementation began with a pilot at the neonatology department. The neonatology department was selected due as it had a smaller number of staff and the department's nurse manager expressed strong support and was a natural project champion. In January 2014, three training sessions were conducted at different times in order to capture all department clinical staff from different shifts. Immediately following the training, hand sanitizer bottles were distributed to the neonatology department. The request and distribution processes were studied. Feedback and suggestions were collected from the department; the process was modified accordingly before scaling up to other units. The phased implementation gradually rolled out between February 2014 and October 2014 to include all seven inpatient departments, all outpatient areas, as well as administrative offices. In October 2014, all staff have access to hand sanitizer within their department. 


\subsection{Monitoring}

The MDT created a monitoring system to ensure successful implementation. The monitoring system included tracking the consumption of hand sanitizer as well as hand-hygiene audits. The pharmacy department recorded the amount and frequency of hand sanitizer distributed to individual departments. In January 2014, the MDT developed an auditing tool (Appendix 2) by modifying the WHO 5 Moments for Hand Hygiene auditing form. The audits were conducted by an HRH infection prevention nurse specialist and an infection prevention officer. They observed the health care providers as well as the patients and visitors in hand washing practice. The opportunities and actual hand hygiene practices were recorded on the auditing tool. The Infection Prevention and Control committee also incorporated this ongoing monthly hand hygiene compliance audits into their routine hospital surveillance. The information collected was presented to all the staff during their monthly quality improvement meetings with the objective of providing feedback to individual departments to encourage performance.

The overall program evaluation was conducted to examine the effect on the hand-hygiene practice compliance in the hospital. The hand-hygiene observation audits in January and February 2014 served as the pre-intervention baseline data and the audits between February and May 2015 served as post-intervention data.

\section{Method}

\subsection{Data Measure}

The hand-hygiene compliance rates among the health care workers, visitors and patients were measured two months before the intervention and again for four months post intervention in order to evaluate if the intervention was effective in improving the hand hygiene practice in the hospital. The hand hygiene compliance data were collected using the auditing tool. The tool included the opportunities of hand hygiene opportunities observed and hand hygiene practice observed; and further divided by the participants' professional categories. The hand hygiene compliance is calculated by dividing the number of hand hygiene practice by the number of hand hygiene opportunities observed. The volume of hand sanitizer used was also recorded to assess utilization as well as to provide planning information for future use.

\subsection{Data Analysis}

The hand hygiene practice compliance rates pre and post intervention were compared using Chi-square test. All data analysis was completed using SPSS v.20 statistical software at a significance level of $\mathrm{P}=0.05$.

\section{Results}

As of October 2014, hand sanitizer has been made available to all inpatient, outpatient and administrative departments. Sensitization training sessions were provided to $100 \%$ of the hospital clinical staff. The production team has scheduled to produce sanitizer weekly as dictated by demand.

The tracking records showed on average the production team manufactured approximately 100 liters of hand sanitizer weekly.

In the two-month pre-intervention period, 1042 hand hygiene opportunities were observed while 4598 hand hygiene opportunities were observed in the four-month post-intervention period. Observations were conduction on physicians (pre: 355, post: 1489), nurses (pre: 514, post: 2425), other staff members (pre: 18, post: 70), students (pre: 42, post: 180), visitors (pre: 64, post: 222) and patients (pre: 49, post: 210). The pre- and post-intervention sample did not differ statistically by the categories $(P=0.324)$.

The overall hand-hygiene compliance using any method significantly increased from $59 \%$ pre-intervention to $67 \%$ post intervention $(P<0.001)$. Specifically, the use of hand sanitizer for hand hygiene significantly increased from $46 \%$ to $58 \%(P<0.001)$. The hand washing rate did not change in a statistically significant manner with $16 \%$ during pre-intervention and $10 \%$ in the post-intervention, $P=0.369$.

The hand hygiene compliance rates among physicians and nurses showed statistically significant improvement from $66 \%$ to $76 \%$ for physicians $(P<0.001)$, and $66 \%$ to $73 \%$ for nurses $(P=0.002)$. The hand hygiene compliance rates among other staff, students, visitor and patients all showed slight increase from pre- to postintervention, although statistical significance cannot be detected. 
Hand hygiene compliance rates were highest among physicians (66\% pre- and 76\% post-) and nurses (66\% pre- and $73 \%$ post-) and lowest among other staff (11\% pre- and $16 \%$ post) in pre- and post-intervention periods.

For the specific moments of hand hygiene, statistic significant improvements were detected for before touching patients ( $48 \%$ pre- to $60 \%$ post-intervention, $P<0.001$ ), after touching patients (59\% pre to $72 \%$ post-intervention, $P<0.001$ ), and after touching patients' immediate surroundings (54\% pre to $62 \%$ post-intervention, $P$ $<0.019$ ).

The highest rate of hand hygiene compliance occurred after touching patients' body fluid (81\%) and the lowest rate occurred before touching patient (48\%) in the pre intervention period. While in the post-intervention period, the highest hand hygiene compliance rate occurred before performing clean procedure (82\%) and the lowest rate remained for occurred before touching patient (60\%). Results were summarized in Table 1.

Table 1. Summary of pre- and post-intervention results.

\begin{tabular}{|c|c|c|c|c|c|c|}
\hline \multirow{2}{*}{ Sample } & \multirow{2}{*}{$(\mathrm{N})$} & \multirow{2}{*}{\multicolumn{2}{|c|}{$\begin{array}{c}\text { Pre-intervention } \\
1042\end{array}$}} & \multirow{2}{*}{\multicolumn{2}{|c|}{$\begin{array}{c}\text { Post-intervention } \\
4596\end{array}$}} & \multirow{2}{*}{ P-value } \\
\hline & & & & & & \\
\hline & Physician & 355 & $(34 \%)$ & 1489 & (32\%) & \multirow{6}{*}{0.324} \\
\hline & Nurse & 514 & $(49 \%)$ & 2425 & $(53 \%)$ & \\
\hline & Other staff & 18 & $(2 \%)$ & 70 & $(2 \%)$ & \\
\hline & Student & 42 & $(4 \%)$ & 180 & $(4 \%)$ & \\
\hline & Patient & 49 & $(5 \%)$ & 210 & $(5 \%)$ & \\
\hline & Visitor & 64 & $(6 \%)$ & 222 & $(5 \%)$ & \\
\hline \multicolumn{7}{|l|}{ HH Compliance } \\
\hline \multirow[t]{2}{*}{ Overall } & HH compliance & 617 & $(59 \%)$ & 3102 & (67\%) & \multirow{2}{*}{$<0.001^{* *}$} \\
\hline & Non compliance & 425 & $(41 \%)$ & 1496 & (33\%) & \\
\hline \multirow[t]{3}{*}{ Method } & Hand washing & 142 & $(16 \%)$ & 452 & $(10 \%)$ & 0.369 \\
\hline & Using hand sanitizer & 475 & $(46 \%)$ & 2650 & $(58 \%)$ & $<0.001^{* *}$ \\
\hline & Non compliance & 425 & $(41 \%)$ & 1496 & (33\%) & Reference \\
\hline \multicolumn{7}{|l|}{ Subject category } \\
\hline \multirow[t]{2}{*}{ Physician } & HH compliance & 235 & $(66 \%)$ & 1135 & $(76 \%)$ & \multirow{2}{*}{$<0.001^{* *}$} \\
\hline & Non compliance & 120 & $(34 \%)$ & 354 & $(24 \%)$ & \\
\hline \multirow[t]{2}{*}{ Nurse } & HH compliance & 340 & $(66 \%)$ & 1764 & $(73 \%)$ & \multirow{2}{*}{$0.002^{* *}$} \\
\hline & Non compliance & 174 & $(34 \%)$ & 661 & (27\%) & \\
\hline \multirow[t]{2}{*}{ Other staff } & HH compliance & 2 & $(11 \%)$ & 11 & $(16 \%)$ & \multirow{2}{*}{0.475} \\
\hline & Non compliance & 16 & $(89 \%)$ & 59 & $(84 \%)$ & \\
\hline \multirow[t]{2}{*}{ Student } & HH compliance & 10 & $(24 \%)$ & 53 & $(29 \%)$ & \multirow{2}{*}{0.299} \\
\hline & Non compliance & 32 & $(76 \%)$ & 127 & $(71 \%)$ & \\
\hline \multirow[t]{2}{*}{ Patient } & HH compliance & 18 & $(37 \%)$ & 86 & $(41 \%)$ & \multirow{2}{*}{0.354} \\
\hline & Non compliance & 31 & $(63 \%)$ & 124 & $(59 \%)$ & \\
\hline \multirow[t]{2}{*}{ Visitor } & HH compliance & 12 & $(19 \%)$ & 51 & $(23 \%)$ & \multirow{2}{*}{0.287} \\
\hline & Non compliance & 52 & $(81 \%)$ & 171 & $(77 \%)$ & \\
\hline \multicolumn{7}{|l|}{ Moments } \\
\hline \multirow[t]{2}{*}{ Before touching patient } & HH compliance & 154 & $(48 \%)$ & 846 & $(60 \%)$ & \multirow{2}{*}{$<0.001^{* *}$} \\
\hline & Non compliance & 170 & $(52 \%)$ & 562 & $(40 \%)$ & \\
\hline \multirow[t]{2}{*}{ Before clean procedure } & HH compliance & 128 & $(79 \%)$ & 586 & $(82 \%)$ & 0425 \\
\hline & Non compliance & 34 & $(21 \%)$ & 130 & $(18 \%)$ & 0.435 \\
\hline After touching body fluid & HH compliance & 79 & $(81 \%)$ & 182 & $(72 \%)$ & 0103 \\
\hline & Non compliance & 19 & $(19 \%)$ & 71 & $(28 \%)$ & 0.100 \\
\hline After touching patient & HH compliance & 119 & $(59 \%)$ & 826 & $(72 \%)$ & $<0001^{* *}$ \\
\hline & Non compliance & 84 & $(41 \%)$ & 324 & $(28 \%)$ & \\
\hline After touching patient surrounding & HH compliance & 137 & $(54 \%)$ & 662 & $(62 \%)$ & $0019^{* *}$ \\
\hline & Non compliance & 118 & $(46 \%)$ & 409 & (38\%) & 0.019 \\
\hline
\end{tabular}




\section{Successes, Challenges and Lessons Learned}

Our project significantly increased the hand-hygiene compliance of hospital staff in the hospital. The success was specifically contributed to the availability of hand sanitizer, as the results showed hand-hygiene compliance increased with the use of hand sanitizer, not with hand washing. By providing the needed supplies and trainings, the MDT created an enabling environment to encourage positive behavior. The project provided cost effective access of hand sanitizer to all staff. This showed a well-designed project with team-based planning and implementation can successfully compensate for the lack of hand washing stations in the hospital.

Similar to other sustainable hand-hygiene practice interventions, this project adopted a multimodal approach [5] [11] [15] [16] [30]-[32]. The MDT provided training to the staff and put posters on the walls in various locations. Training was attended mostly by physicians and nurses. Both of them showed significant improvement in hand hygiene practice after the intervention. Other staff, students, visitors and patients did not show significant improvement in the hand hygiene practice. For students, patients and visitors, their understanding on using hand sanitizer for hand hygiene would rely mainly on them reading the posters or verbally reminded by nurses. Staff other than nurses and physicians, the reasons for their consistently low hand hygiene compliance should definitely be considered for further studies.

Our data showed the hand-hygiene practices have significantly improved in three specific moments: before touching a patient, after touching a patient, and after touching a patient's surrounding - these are easy to forget as sometimes when patients are not visibly dirty, people tend to forget about hand hygiene. Moreover, people usually did not realize touching patient's surrounding can be a source of infection. By providing training to remind them these specific moments, the hand hygiene practice of these three moments is improved. The handhygiene compliance after touching bodily fluid is consistently the highest when compared to all other moments despite not changing significantly. This is easy to understand as when one is in contact with body fluid, there is a natural tendency to clean hands thus giving higher hand-hygiene compliance rate even before implementation.

The project utilized many basic quality improvement principles to address hospital hand-hygiene compliance issue-which is a world-wide safety concern of patients, staff and families. A MDT included members who were facing the problems of poor hand hygiene on a day-to-day basis to devise and implement evidence-based interventions and to monitor changes. Strong internal champions (hospital and department leadership) took real ownership of the project. Utilizing the readily available WHO guidelines and formula and incorporating the hand sanitizer into existing hospital system all contributed to the success of the program.

The project was in-line with the hospital vision: to obtain hospital accreditation. As such, the support from senior leadership was almost guaranteed. Implementing the project in phases allowed the MDT to quickly identify challenges and make modification according to learning's immediately, resulting in some appropriate adjustments to process and tools in timely manner. For example, during the pilot stage of the implementation, the MDT found some of the staff in the neonatology department were not using the hand sanitizer despite the availability. The neonatology staff informed the MDT that they thought the sanitizer was spoiled due to the foul smell. The MDT conducted research and realized one of the ingredients of the hand sanitizer, peroxide, could general foul smell after approximately three days and grow stronger with time. The MDT quickly changed the manufacture and ordering cycle, asking the departments to order more frequently but in less quantity each time.

Since the hospital staff were involved in this project from the planning through implementation to evaluation, they developed strong ownership and commitment to this project and continue to sustain the in-house hand sanitizer production system. The monthly hand-hygiene audit has become a routine hospital quality measure despite changes in human resource. By teaching the MDT how to apply quality improvement principles to solve problems and focusing on system change, the project help developed the leadership and management capacity of the hospital. This is critical to the sustainability of the project.

The interventions required some initial investment cost. The one-time purchase of bottles and dispensers cost the hospital approximately 450 USD. However, for the monthly 100 liters of hand sanitizer consumed, the hospital is saving approximately 650 USD (71\% less than a purchased commercial product). Such monthly saving was more than sufficient to cover the initial investment within the first month of implementation - which was critical to the project's feasibility and ultimate success.

We acknowledge the use of hand sanitizer is not a replacement for running water in the hospital. However, with the lack of proper infrastructure, making hand sanitizer available is an acceptable alternative to improve the infection prevention and control standard. Despite saving $71 \%$ of the cost by in-house manufacturing the hand 
sanitizer, the hospital still has to commit to the ingredient cost. This project also did not assess the hospital acquired infection rate as a measure to show the actual impact.

\section{Conclusion}

The production of hand sanitizer within a health care facility is cost effective and is feasible to integrate into existing operations. This intervention has the potential to have a high impact for a relatively low investment of financial and organizational resources. The impact is especially high in facilities where there are inadequate hand hygiene resources, such as functioning sinks, water, soap and paper towels. The staff and administration have positive response to the introduction of this initiative. The team is working with the Rwandan Ministry of Health to introduce the program to all public hospitals as a national program.

\section{References}

[1] Arnow, P.M., Quimosing, E.M. and Beach, M. (1993) Consequences of Intravascular Catheter Sepsis. Clinical Infectious Diseases, 16, 778-784.

[2] Scott, R.D. (2009) The Direct Medical Costs of Healthcare-Associated Infections in U.S. Hospitals and the Benefits of Prevention. Division of Healthcare Quality Promotion National Center for Preparedness, Detection, and Control of Infectious Diseases Coordinating Center for Infectious Diseases Centers for Disease Control and Prevention, Atlanta.

[3] (2015) WHO Collaborating Centre for Patient Safety Solutions Aide Memoir. http://www.who.int/patientsafety/implementation/solutions/patientsafety/PSP_H5-Solutions_Report-fnl-sumry_Apr-20 12.pdf

[4] Abramczyk, M.L., Carvalho, W.B., Carvalho, E.S. and Medeiros, E.A. (2003) Nosocomial Infection in a Paediatric Intensive Care Unit in a Developing Country. Brazilian Journal of Infectious Diseases, 7, 375-380.

[5] Lautenbach, E. (2001) Chapter 12. Practices to Improve Handwashing Compliance. In: Shojania, K.G., Duncan, B.W., McDonald, K.M., Wachter, R.M. and Markowitz, A.J., Eds., Making Healthcare Safer: A Critical Analysis of Patient Safety Practices, Agency for Healthcare Research and Quality. http://archive.ahrq.gov/clinic/ptsafety/

[6] Jarvis, W.R. (1996) Selected Aspects of the Socioeconomic Impact of Nosocomial Infections: Morbidity, Mortality, Cost, and Prevention. Infection Control and Hospital Epidemiology, 17, 552-557. http://dx.doi.org/10.2307/30141291

[7] Klevens, R.M., Edwards, J.R., Richards Jr., C.L., Horan, T.C., Gaynes, R.P., Pollock, D.A. and Cardo, D.M. (2007) Estimating Health Care-Associated Infections and Deaths in U.S. Hospitals, 2002. Public Health Reports, 122, 160-166.

[8] Richard, A., Polin, S., et al. (2012) Epidemiology and Diagnosis of Health Care-Associated Infections in the NICU: A Technical Report from the American Academy of Pediatrics.

[9] World Health Organization (2002) Prevention of Hospital Acquired Infections. http://www.who.int/csr/resources/publications/whocdscsreph200212.pdf

[10] Bagheri, N.S., Allegranzi, B., Syed, S.B., Ellis, B. and Pittel, D. (2011) Health-Care-Associated Infection in Africa: A Systematic Review. Bulletin of the World Health Organization, 89, 757-765. http://dx.doi.org/10.2471/BLT.11.088179

[11] WHO (2009) WHO Guidelines on Hand Hygiene in Health Care: First Global Patient Safety Challenge Clean Care Is Safer Care. WHO, Geneva.

[12] Centers for Disease Control and Prevention (2014) Hand Hygiene in Health Care Settings: Hand Hygiene Basics. http://www.cdc.gov/handhygiene/Basics.html

[13] National Quality Forum (2010) Safe Practices for Better Healthcare: 2010 Update. http://www.qualityforum.org/Publications/2010/04/Safe_Practices_for_Better_Healthcare_\%E2\%80\%93_2010_Updat e.aspx

[14] Squires, J.E., Suh, K.N., Linklater, S., Bruce, N., Gartke, K., Graham, I.D., Karovitch, A., Read, J., Virginia Roth, V., Stockton, K., Tibbo, E., Woodhall, K., Worthington, J. and Grimshaw, J.M. (2013) Improving Physician Hand Hygiene Compliance Using Behavioural Theories: A Study Protocol. Implementation Science, 8, 16. http://dx.doi.org/10.1186/1748-5908-8-16

[15] Allegranzi, B. and Pittet, D. (2009) Role of Hand Hygiene in Healthcare-Associated Infection Prevention. Journal of Hospital Infection, 73, 305-315. http://dx.doi.org/10.1016/j.jhin.2009.04.019

[16] Pincock, T., Bernstein, P., Warthman, S. and Holst, E. (2012) Bundling Hand Hygiene Interventions and Measurement to Decrease Health Care-Associated Infections. American Journal of Infection Control, 40, S18-S27. http://dx.doi.org/10.1016/j.ajic.2012.02.008

[17] Backman, C., Zoutman, D.E. and Marck, P.B. (2008) An Integrative Review of the Current Evidence on the Relation- 
ship between Hand Hygiene Interventions and the Incidence of Health Care-Associated Infections. American Journal of Infection Control, 36, 333-348. http://dx.doi.org/10.1016/j.ajic.2007.08.007

[18] McGuckin, M., Waterman, R. and Govednik, J. (2009) Hand Hygiene Compliance Rates in the United States-A One-Year Multicenter Collaboration Using Product/Volume Usage Measurement and Feedback. American Journal of Medical Quality, 24, 205-213. http://dx.doi.org/10.1177/1062860609332369

[19] Berg, D.E., Hershow, R.C., Ramirez, C.A. and Weinstein, R.A. (1995) Control of Nosocomial Infections in an Intensive Care Unit in Guatemala City. Clinical Infectious Diseases, 21, 588-593. http://dx.doi.org/10.1093/clinids/21.3.588

[20] Pittet, D., Hugonnet, S., Harbarth, S., Mourouga, P., Sauvan, V., Touveneau, S. and Perneger, T.V. (2000) Effectiveness of a Hospital-Wide Programme to Improve Compliance with Hand Hygiene. Infection Control Programme. Lancet, 356, 1307-1312. http://dx.doi.org/10.1016/S0140-6736(00)02814-2

[21] Johnson, P.D., Martin, R., Burrell, L.J., Grabsch, E.A., Kirsa, S.W., O’Keeffe, J., Mayall, B.C., Edmonds, D., Barr, W., Bolger, C., Naidoo, H. and Grayson, M.L. (2005) Efficacy of an Alcohol/Chlorhexidine Hand Hygiene Program in a Hospital with High Rates of Nosocomial Methicillin-Resistant Staphylococcus aureus (MRSA) Infection. Medical Journal of Australia, 183, 509-514.

[22] Grayson, M.L., Jarvie, L.J., Martin, R., Johnson, P.D., Jodoin, M.E., McMullan, C., Gregory, R.H., Bellis, K., Cunnington, K., Wilson, F.L., Quin, D. and Kelly, A.M. (2008) Significant Reductions in Methicillin-Resistant Staphylococcus aureus Bacteraemia and Clinical Isolates Associated with a Multisite, Hand Hygiene Culture-Change Program and Subsequent Successful Statewide Roll-Out. Medical Journal of Australia, 188, 633-640.

[23] Allegranzi, B., Sax, H., Bengaly, L., Richet, H., Minta, D.K., Chraiti, M.N., Sokona, F.M., Gayet-Ageron, A., Bonnabry, P. and Pittet, D. (2010) Successful Implementation of the World Health Organization Hand Hygiene Improvement Strategy in a Referral Hospital in Mali, Africa. Infection Control \& Hospital Epidemiology, 31, 133-141. http://dx.doi.org/10.1086/649796

[24] Erasmus, V., Daha, T.J., Brug, H., Richardus, J.H., Behrendt, M.D., Vos, M.C. and van Beeck, E.F. (2010) Systematic Review of Studies on Compliance with Hand Hygiene Guidelines in Hospital Care. Infection Control \& Hospital Epidemiology, 31, 283-294. http://dx.doi.org/10.1086/650451

[25] Yawson, A.E. and Hesse, A.A.J. (2013) Hand Hygiene Practices and Resources in a Teaching Hospital in Ghana. Journal of Infection in Developing Countries, 7, 338-347. http://dx.doi.org/10.3855/jidc.2422

[26] Endalafer, N., Solomon, G.-S. and Berhanu, K. (2011) Nosocomial Bacterial Infections in a Tertiary Hospital in Ethiopia. Journal of Infection Prevention, 12, 38-43. http://dx.doi.org/10.1177/1757177410376680

[27] Marjadi, B. and McLaws, M.L. (2010) Hand Hygiene in Rural Indonesia: Barriers beyond Sinks, Hand Rubs and In-Service Training. Journal of Hospital Infection, 76, 256-260. http://dx.doi.org/10.1016/j.jhin.2010.06.021

[28] Owusu-Ofori, A., Jennings, R., Burgess, J., Prasad, P.A., Acheampong, F. and Coffin, S.E. (2010) Assessing Hand Hygiene Resources and Practices at a Large African Teaching Hospital. Infection Control \& Hospital Epidemiology, 31, 802-808. http://dx.doi.org/10.1086/654005

[29] Allegranzi, B., Bagheri Nejad, S., Combescure, C., Graafmans, W., Attar, H., Donaldson, L. and Pittet, D. (2011) Burden of Endemic Health-Care-Associated Infection in Developing Countries: Systematic Review and Meta-Analysis. Lancet, 377, 228-241. http://dx.doi.org/10.1016/S0140-6736(10)61458-4

[30] Gould, D.J., Moralejo, D., Drey, N. and Chudleigh, J.H. (2010) Interventions to Improve Hand Hygiene Compliance in Patient Care. Cochrane Database of Systematic Reviews, No. 9, CD005186. http://dx.doi.org/10.1002/14651858.cd005186.pub3

[31] Rosenthal, V.D., Pawar, M., Leblebicioglu, H., Navoa-Ng, J.A., Villamil-Gómez, W., Armas-Ruiz, A., Cuéllar, L.E., Medeiros, E.A., Mitrev, Z., Gikas, A., Yang, Y., Ahmed, A., Kanj, S.S., Dueñas, L., Gurskis, V., Mapp, T., Guanche-Garcell, H., Fernández-Hidalgo, R. and Kübler, A. (2013) Impact of the International Nosocomial Infection Control Consortium (INICC) Multidimensional Hand Hygiene Approach over 13 Years in 51 Cities of 19 Limited-Resource Countries from Latin America, Asia, the Middle East, and Europe. Infection Control \& Hospital Epidemiology, 34, 415-423. http://dx.doi.org/10.1086/669860

[32] Barrera, L., Zingg, W., Mendez, F. and Pittet, D. (2011) Effectiveness of a Hand Hygiene Promotion Strategy Using Alcohol-Based Handrub in 6 Intensive Care Units in Colombia. American Journal of Infection Control, 39, 633-639. http://dx.doi.org/10.1016/j.ajic.2010.11.004

[33] Aiken, A.M., Wanyoro, A.K., Mwangi, J., Juma, F., Mugoya, I.K. and Scott, J.A. (2013) Changing Use of Surgical Antibiotic Prophylaxis in Thika Hospital, Kenya: A Quality Improvement Intervention with an Interrupted Time Series Design. PLoS ONE, 8, e78942.

[34] Allegranzi, B. and Pittet, D. (2009) Role of Hand Hygiene in Healthcare-Associated Infection Prevention. The Journal of Hospital Infection, 73, 305-315. http://dx.doi.org/10.1016/j.jhin.2009.04.019

[35] Allegranzi, B., Sax, H., Bengaly, L., Richet, H., Minta, D.K., Chraiti, M.N., Sokona, F.M., Gayet-Ageron, A., Bonna- 
bry, P. and Pittet, D. (2010) Successful Implementation of the World Health Organization Hand Hygiene Improvement Strategy in a Referral Hospital in Mali, Africa. Infection Control \& Hospital Epidemiology, 31, 133-141. http://dx.doi.org/10.1086/649796

[36] Binagwaho, A., Kyamanywa, P., Farmer, P.E., Nuthulaganti, T., Umubyeyi, B., Nyemazi, J.P., Mugeni, S.D., Asiimwe, A., Ndagijimana, U., Lamphere McPherson, H., Ngirabega Jde, D., Sliney, A., Uwayezu, A., Rusanganwa, V., Wagner, C.M., Nutt, C.T., Eldon-Edington, M., Cancedda, C., Magaziner, I.C. and Goosby, E. (2013) The Human Resources for Health Program in Rwanda-New Partnership. The New England Journal of Medicine, 369, 2054-2059. http://dx.doi.org/10.1056/NEJMsr1302176

[37] WHO (2010) Guide to Local Production: WHO-Recommended Handrub Formulations. Patient Safety, a World Alliance for Safer Health Care. 1-9. 


\section{Appendix 1}

Recommended formula for 10 liter production of hand sanitizer:

\begin{tabular}{cc}
\hline Ingredient & Qty (ml) \\
\hline Ethanol 96\% & 8333 \\
Hydrogen peroxide 3\% & 417 \\
Glycerol 98\% & 145 \\
Distill water & 1105 \\
Total volume & 10,000 \\
\hline
\end{tabular}

\section{Appendix 2}

Hand hygiene auditing form.

\begin{tabular}{|c|c|c|c|c|c|c|c|c|c|c|c|c|c|}
\hline \multicolumn{14}{|c|}{$\begin{array}{l}\text { Observer: } \\
\text { Date: } \_ \text {Time: } \_ \text {Dept: } \\
\text { HH resources: ___ }\end{array}$} \\
\hline \multirow{2}{*}{ Moment/Method } & & \multicolumn{2}{|c|}{ DOCTOR } & \multicolumn{2}{|c|}{ NURSE } & \multicolumn{2}{|c|}{ PATIENT } & \multicolumn{2}{|c|}{ STAFF } & \multicolumn{2}{|c|}{ STUDENT } & \multicolumn{2}{|c|}{ VISITOR } \\
\hline & & YES & NO & YES & NO & YES & NO & YES & No & YES & No & YES & NO \\
\hline $\begin{array}{c}\text { BEFORE } \\
\text { touching a patient }\end{array}$ & $\begin{array}{l}\text { WASH } \\
\text { RUB }\end{array}$ & & & & & & & & & & & & \\
\hline $\begin{array}{l}\text { BEFORE “Clean” } \\
\text { procedure }\end{array}$ & $\begin{array}{c}\text { WASH } \\
\text { RUB }\end{array}$ & & & & & & & & & & & & \\
\hline $\begin{array}{c}\text { AFTER PATIENT } \\
\text { body fluid } \\
\text { exposure risk }\end{array}$ & $\begin{array}{l}\text { WASH } \\
\text { RUB }\end{array}$ & & & & & & & & & & & & \\
\hline $\begin{array}{l}\text { AFTER PERSONAL } \\
\begin{array}{c}\text { body fluid } \\
\text { exposure risk }\end{array}\end{array}$ & $\begin{array}{l}\text { WASH } \\
\text { RUB }\end{array}$ & & & & & & & & & & & & \\
\hline $\begin{array}{l}\text { AFTER touching } \\
\text { a patient }\end{array}$ & $\begin{array}{l}\text { WASH } \\
\text { RUB }\end{array}$ & & & & & & & & & & & & \\
\hline $\begin{array}{l}\text { AFTER touching } \\
\text { patient surroundings }\end{array}$ & $\begin{array}{l}\text { WASH } \\
\text { RUB }\end{array}$ & & & & & & & & & & & & \\
\hline
\end{tabular}

